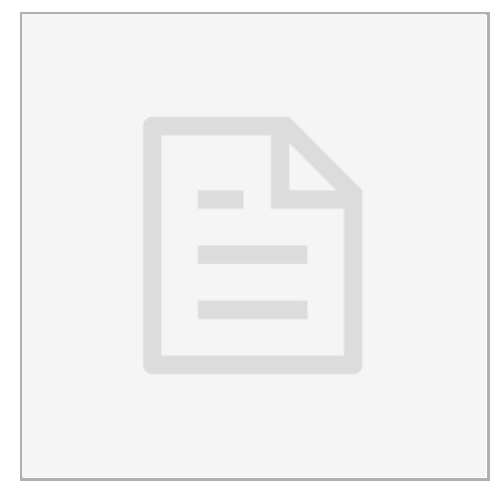

MAY 18, 2021

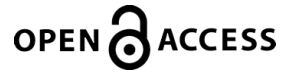

DOI:

dx.doi.org/10.17504/protocol s.io.bfznjp5e

Protocol Citation: Brett Hanzlicek, Anna Rietsch, Margot Damaser 2021. SPARC Cat - Sham Control Chronic Cat 2, Day 14. protocols.io

https://dx.doi.org/10.17504/p rotocols.io.bfznjp5e

License: This is an open access protocol distributed under the terms of the Creative Commons Attribution License, which permits unrestricted use, distribution, and reproduction in any medium, provided the original author and source are credited

Protocol status: Working We use this protocol and it's working

Created: May 05, 2020

Last Modified: May 18, 2021

PROTOCOL integer ID: 36622

\section{(3) SPARC Cat - Sham Control Chronic Cat 2, Day 14}

\section{Brett Hanzlicek $^{1}$, Anna Rietsch ${ }^{2}$, Margot Damaser ${ }^{2}$ \\ ${ }^{1}$ Advanced Platform Technology Center, Louis Stokes VA Hospital, Cleveland, Ohio; \\ ${ }^{2}$ Department of Biomedical Engineering, Cleveland Clinic Lerner Research Institute, Cleveland, Ohio}

\section{SPARC}

Tech. support email: info@neuinfo.org

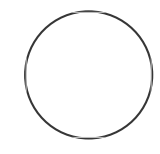

Brett Hanzlicek

\section{ABSTRACT}

This is a procedure for a sham control chronic cat experiment (Day 14) for cystotomy (bladder surgery). The cystotomy is performed without UroMOCA implantation. The cat is observed daily and imaged on day 0,14 and 30 to track changes to the bladder and overall cat health in response to the cystotomy. This protocol includes urodynamics and imaging for Day 14 in the chronic experiments.

\section{MATERIALS}

Cat - Domestic short-haired cat. Male or female. 6-24 months; $3.5-5.0 \mathrm{~kg}$

Syringe Pump - Genie Touch; Kent Scientific

Pressure Transducer - Catalog \# 503067

WPI Amplifier - 4 channel transbridge

WPI National Instruments multifunction I/O device - NI USB 6259

National Instruments Laptop with Labview software

Tubing - Masterflex L/S Platinum-Cured Silicone Tubing ID 3/16 "; Cole Parmer

BNC cables

Tubing to catheter - APIS

Laborie Catheter - Argyl Suction Catheter, 3.5 Fr Catalog \# 8890703211

Covidien Sutures - 4-0 Vicryl Polysorb (Covidien UL212)

3-0 Prolene (Ethicon 8762)

2-0 Silk Syringe

$60 \mathrm{ml}$ Contrast

Visipaque $320 \mathrm{mg} / \mathrm{ml}$

Surgilube

Surgical instruments 


\section{BEFORE START INSTRUCTIONS}

1 week before start of experiment - Confirm absence of bladder spasm; healthy cat

12 hours before experiment, start fasting the cat

You must transport the animal chart along with the cat to surgery site. The veterinary team will record all relevant data in the chart. The chart must then go back to the housing site.

\section{Transport Cat}

1 Transport cat from housing site to surgery site.

\section{Animal Prep and catheter placement}

2 Animal is anesthetized and abdomen is shaved by the vet team. The cat is then moved into the surgery room and attached to monitors by the vet team.

3 Drape animal and perform betadine scrub on abdomen and genitals.

4 Put surgilube on 3.5Fr catheter and insert into bladder through the urethra. Advance the catheter until resistance is met, then pull back $2-3 \mathrm{~cm}$.

5 Use gentle suction with syringe to withdraw urine from bladder through the catheter. Measure the volume and save the urine for urinalysis.

I $6 \mathrm{~mL}$ urine removed

\section{Cystogram - DYNA CT}

6 Use 1:5 dilution of contrast to saline to visualize bladder. 
Fill the bladder with $\triangle 10 \mathrm{~mL}$ contrast and take a single CT image.

Add $\triangle 5 \mathrm{~mL}$ more to bladder (total of $15 \mathrm{ml}$ ) and take single CT image

Take a 3D CT image with $15 \mathrm{ml}$ contrast:saline in the bladder

$7 \quad$ Empty Bladder

\section{Urodynamics/Cystometry 1}

8

Note

Performed after cat is transferred from Isoflurane to propofol anesthetic.

Note

Fill rate is $2 \mathrm{ml}$ saline/minute using syringe pump.

Note

Data is recorded using Labview software.

Note

Pressure is recorded using an external pressure transducer connected to syringe pump on one end and tubing that leads to the catheter on the other end.

9 Fill bladder with saline and record pressure using pressure transducer connected to LabView

Fill to I $15 \mathrm{~mL}$;End round 1 urodynamics 
Tug on catheter after filling to visualize contraction in Labview software

10 Empty Bladder

\section{Urodynamics/cystometry 2}

11 Fill bladder with saline at $2 \mathrm{ml} / \mathrm{min}$

12 Fill to $\triangle 15 \mathrm{~mL}$; End round 2 urodynamics

\section{Wake and return cat}

13 Wait for cat to wake up and return to housing site. 